\title{
Toward an Integrative Perspective on Social Learning in System Innovation Initiatives
}

\author{
Pieter J. Beers ${ }^{1,2}$, Barbara van Mierlo ${ }^{2}$ and Anne-Charlotte Hoes ${ }^{2,3}$
}

\begin{abstract}
Sustainability transitions go hand in hand with learning. Theories in the realm of sustainability sciences mostly concentrate on diversity and learning outcomes, whereas theories from the educational sciences mostly focus on learning as an interactive process. In this contribution, we aim to benefit from an integration of these perspectives in order to better understand how different interaction patterns contribute to learning. We studied STAP, an innovation initiative of Dutch greenhouse growers. The Dutch greenhouse sector is predominantly focused on production and efficiency, which causes problems for its future viability. STAP aimed to make the sector more market-oriented while at the same time increasing its societal acceptability (societally responsible innovation). To that end, STAP focused on the development of integrated value chains (primary production, sales, trade) that can contribute to a transition towards a societally sensitive greenhouse sector. As action researchers, we collected extensive transcripts of meetings, interviews, and various other documents. We used an open coding strategy to identify different patterns of interaction and the learning outcomes produced by the initiative. We then linked the interaction patterns to the outcomes. Analysis suggests that seemingly negative attack-and-defend patterns of interaction certainly can result in substantial learning results, while seemingly positive synthetic interaction patterns, where participants strive to build on each other, can result in rather bland interaction without substantial outcomes. The results offer an empirical basis to our approach of linking learning interactions to learning outcomes, and it suggests that learning for sustainability can be enhanced by focusing on interaction patterns.
\end{abstract}

Key Words: Greenhouse growers; innovation; interaction patterns; social learning; sustainability transitions

\section{INTRODUCTION}

The more complex the innovation challenges, the more important the associated learning. Sustainability transitions arguably rank among the most complex innovation challenges (Ison et al. 2007, Veldkamp et al. 2009). A sustainability transition concerns a structural change in system structure, culture, and practice toward a more sustainable (dynamic) state (Loorbach and Rotmans 2006). Sustainability transitions are characterized by high levels of uncertainty and controversy that render them unfit for traditional government approaches. Steering options toward sustainability are very limited. They include experimentation, future visioning, and learning (Loorbach and Rotmans 2006). Indeed, learning processes are often mentioned as key to sustainability transitions. However, learning itself has received little conceptualization and operationalization in the sustainability transitions literature - apart from some notable exceptions (e.g., Raven et al. 2008, Van Mierlo et al. 2010b). A better understanding of the role of learning may improve innovators' ability to stimulate learning in sustainability transitions.

Various established scientific theories have contributed to the understanding of learning in general. However, they widely differ in how they conceptually approach learning and hence they vary in relevance for sustainability transitions as well. Our work combines two existing bodies of literature about learning in order to contribute to a better understanding of learning in sustainability transitions. The conceptualization of social learning in natural resources management, which focused primarily on learning outcomes, will be complemented with educational approaches to collaborative learning, which highlight the process of learning.

We develop an integrative approach to learning in the context of sustainability transitions that takes into account both process and outcomes of learning by enriching social learning theory with insights from educational sciences. The main underlying assumption is that in the process of learning different types or patterns of communicative interaction can be distinguished, which have specific roles in producing learning outcomes. Our aims are twofold: (1) to develop a new theoretical approach that takes on an integrative perspective on learning, and (2) to operationalize that into a framework and explore it empirically. This framework is applied to a case of system innovation by private partners in the Dutch greenhouse sector as an initial test for our framework. The Dutch greenhouse sector is a high-tech, energy intensive agricultural sector, responsible for $10 \%$ of total Dutch yearly gas consumption (Van der Velden and Smit 2014), but also marked by initiatives to use greenhouses to produce energy and to reduce food waste. We explore the framework by studying which interaction patterns stimulate social learning outcomes in the case study, with the following research question: how can social learning be characterized in terms of different patterns of communicative interaction, and how are these patterns related to social learning outcomes? Our intended contribution is to inspire further hypothesizing about social learning. The study is not intended for drawing general conclusions about social learning. 
We first describe learning in the traditions of natural resources management and educational sciences, upon which we build our integrative framework of learning. Then we introduce our methods and our transition case of Dutch greenhouse growers. We report on types of interaction, learning outcomes, and impacts from that case. We discuss the findings in the light of existing theories and their meaning for sustainability transitions.

\section{Social learning in natural resources management}

The concept of social learning is often used in the context of complex societal problems and has received a lot of attention from researchers studying natural resources management (e.g., PahlWostl 2006, Ison et al. 2007, Rodela 2011). It emphasizes the importance of integrating knowledge from multiple perspectives in order to identify ways of dealing with complex problems. Social learning occurs when a heterogeneous set of actors share their knowledge in an interactive process to produce new knowledge and trust that, in turn, serve as the basis for joint action (PahlWostl 2006). Social learning theory treats actor diversity in terms of knowledge, values, interests, and goals as an important prerequisite for the ability to deal with complex issues (Ison and Watson 2007, Wals 2007).

Literature from natural resources management research typically views social learning in terms of its inputs and outcomes, with stakeholder diversity (knowledge, interests, values, resources) as the input and novel solutions to complex societal problems as outcomes. Most authors distinguish conceptual from relational outcomes of social learning (Pahl-Wostl 2006). The conceptual outcomes concern, for instance, new insights and innovative solutions for sustainability issues. These can be seen as the knowledge content of social learning. The relational outcomes refer to the emergent social networks that form as stakeholders become aware of their mutual interdependencies.

Reed et al. (2010) and several others (e.g., Armitage et al. 2008, Cundill 2010, Rodela 2011, Scholz et al., in press) have criticized social learning literature on both conceptual and methodological grounds. Conceptual criticisms include that (1) social learning as a natural process often gets confused with the facilitation of collaborative processes, that (2) the process of social learning itself has received little, if any, conceptualization and that (3) social learning outcomes are often confused with the impacts of social learning. Methodological criticisms include that social learning research has often been limited to (1) single events instead of longer time spans (longitudinal approaches), (2) single groups instead of broader networks, and (3) workshop settings with strong facilitation instead of natural meetings with no or weak facilitation (without researchers chairing meetings or setting the agenda).

Some recent research does address some of these criticisms. For instance, Lee and Krasny (2015), building on Armitage et al. (2008) and Plummer and FitzGibbon (2008) do distinguish more clearly between learning process and outcomes, using interaction, systems orientation, integration, and reflection for learning process, and single-loop, double-loop, and triple-loop learning for outcomes (cf. Argyris and Schön 1978). Furthermore, a few recent examples show that social learning scholars are using learning theories from other fields. For instance, Krasny and Roth (2010) use situated learning theory (Lave and Wenger 1991) and communities of practice (Wenger 1998) to connect social learning and individual learning and to shed light on the role of interaction in learning. These authors are also among the few that cite sources from educational sciences. Still, beyond mentioning the importance of interaction, they rarely, if at all, conceptualize it in depth.

The criticisms by Reed et al. have consequences for both the understanding and the scientific study of social learning in transitions. For instance, does the term social learning refer to the guided process in a workshop facilitated by researchers or to the natural process as it occurs in meetings in self-organized innovation teams over a longer time? How do we draw the line between learning outcomes and impacts of learning? For instance, if social learning is a basis for joint actions, then should those actions be considered outcomes or impacts of social learning? While the concept of social learning provides an important starting point for our framework, because it acknowledges the existence and relevance of the diversity of perspectives in innovation processes, we turn to other theories to operationalize social learning as a process.

\section{Collaborative learning in educational sciences}

Whereas social learning scholars focus on complex real-world contexts characterized by the diversity within and across societal networks, educational scientists usually concentrate on homogeneous groups in experimental or classroom contexts. Educational scientists use the term social learning to cover a broad range of social learning situations, from teacher-learner situations to learning social entities, and everything in between (Salomon and Perkins 1998). Collaborative learning is usually used more specifically, in the sense of learning together in teams or groups with mostly equal status (Smith and MacGregor 1992, Dillenbourg 1999), and has been defined as "a situation in which two or more people learn or attempt to learn something together" (Dillenbourg 1999:2).

An advantage of educational sciences, for our purposes, is their conceptual treatment and operationalization of learning as a process. Although within educational research different perspectives on the collaborative learning process exist, they share the idea that it entails a discursive process in which participants share personal meanings and co-construct shared meanings (e.g., Baker et al. 1999, Barron 2003, Van den Bossche et al. 2011), as indicated by exploratory questions, handling conflicting understandings, and clarifying contributions. Collaborative learning research often focuses on how discursive interaction relates to learning performance. For instance, Van den Bossche et al. (2011) show that the extent to which meaning is effectively negotiated is related to the extent to which teams establish mutually "shared cognitions" and, ultimately, team effectiveness. They also show how predominantly social factors, such as team psychological safety (Edmondson 1999), influence the learning process.

The study of discursive interaction is one of the central aspects of research on collaborative learning (Sullivan Palincsar 1998). In this sense, collaborative learning concerns a sequence of utterances and associated (individual) cognitive processes within a group through which knowledge is shared and new knowledge is constructed. The sub-field of Computer-Supported Collaborative Learning (CSCL) uses computers to influence 
discursive interaction in ways to improve learning (Kirschner et al. 2004). For instance, CSCL researchers have used sentence openers and other influences on interaction to strengthen argumentation in collaborative learning (e.g., Suthers 2001, Noroozi et al. 2012).

Many operationalizations of collaborative learning have been described within educational sciences. We give two examples, with the aim of illustrating that collaborative learning can be operationalized in many different ways, in line with different perspectives on collaboration (specific perspectives on collaboration yield specific operationalizations of collaborative learning). The first, problem-based learning (Barrows and Tamblyn 1980, Schmidt 1983, Schmidt et al. 2007), sees problemsolving as a specific learning process, and uses a generic task analysis of problem-solving processes to structure a group discussion into seven distinct phases with specific goals and activities. In this case, the collaborative learning process involves different, consecutive phases of group discussion activities. The example of problem-based learning illustrates that learning can be operationalized as a sequence of episodes in a meeting that each deal with a sub-task of a group endeavor.

The second, more detailed example concerns the use of CSCL to support negotiation of meaning. Beers et al. (2008) offer a rather generic analysis of negotiation of common ground as a learning process in which speakers' turns revolve on verifying and clarifying contributions on the one hand, and agreeing and disagreeing with them on the other hand. Beers et al. have shown that learners negotiate more common ground, and share more knowledge when they postpone voicing their opinions, opting instead to verify their understanding of what others have contributed. Beers et al. (2008) also show that facilitation techniques exist that can strengthen the negotiation of common ground. Facilitators can use an initial round of brainstorming as a way to postpone voicing of opinions, and can support asking questions for verification. These interventions should increase the extent to which a group establishes common ground. The research carried out by Van den Bossche et al. (2006) supports the notion that this should also increase group effectiveness. Moreover, Van den Bossche et al. (2006) have shown that a safe environment and a shared belief in the efficacy of the group indeed are positively related to collaborative learning behaviors conducive to negotiating common ground. Such research results offer clear options for facilitators to support groups.

In sum, educational approaches to collaborative learning offer a complementary asset to current theories in the social learning tradition. They demonstrate both the feasibility of a discursive, process-oriented approach to learning (it can be measured, operationalized, and analyzed) and its usefulness (the results yield insights into how to support learning). In our framework, we therefore include a process orientation to learning .

\section{Toward an integrative approach: conceptual considerations}

In line with the collaborative learning approach, we regard social learning as a process of generating new knowledge that takes place in communicative interaction (turns of communicative actions and reactions). In societal change processes, social learning occurs in everyday interaction settings or at organized spaces for innovation rather than in formal educational settings. In such processes, the learning concerns giving meaning to problems, new technology, societal developments, et cetera (Leeuwis and Aarts 2011). This implies that communication itself can be seen as strategic action, meaning that participants do not contribute neutrally to a discussion, but pursue specific goals by framing and using discursive strategies (cf. Edwards and Potter 2001, Dewulf and Bouwen 2012). Viewing social learning as occurring in a process of strategic communicative interaction helps to explain why the same person may voice opposite opinions in different situations; taking different positions in different situations may well serve the same goal.

During social learning, three dimensions of learning may become aligned: (1) new or changed knowledge (the what), (2) new or changed actions (the how), and (3) new or changed relations (the who). These dimensions are aspects of the content of the communicative interaction (i.e., what people talk about). By knowledge, we mean, for instance, new individual or shared information and ideas, but also new problem definitions, ideas for how to solve problems, and shared/ common values. In the learning process, this refers to participants exchanging and producing new knowledge, views, and future visions (Pahl-Wostl 2006, Wals 2007, Ison et al. 2013).

The second dimension of social learning concerns action. Scholars from very different research traditions agree that (social learning-like) interaction processes are often embedded in a realworld context that requires or invites action, for instance, in terms of ongoing experimentation (Bouwen and Taillieu 2004, Ison et al. 2013, Sol et al. 2013). From a discursive perspective, we need to distinguish action in discourse, in the form of proposals, agreements or decisions about action, from real-world action. Hence, we focus on the proposals for real-world actions as they are contributed during communicative interaction, including when they are rejected, and the decisions that may ensue.

The third aspect concerns relations, including identities. Scholars have noted that social learning processes leading to transformative change do not only produce knowledge, but also new relations and new interdependencies between actors (PahlWostl 2006, Van Mierlo et al. 2010a, Leeuwis and Aarts 2011). Discursively, this happens, for example, when external stakeholders are discussed and put in a certain light that changes their relational status, as potential partner or competitor for instance. Similarly, when a previously unknown resource or capability of a participant comes to the fore, this may change his/ her status within a network.

In our view, social learning has resulted in a learning outcome whenever these three threads of social learning are interwoven. This follows on the work of Argyris and Schön (1978; see Kouevi et al. 2011 for an elaboration) who state that people's actions are governed by (1) assumptions regarding the fact or action (what?), (2) the reasons behind the action in terms of causes and consequences (why?), and (3) the strategies to make sure that the action takes place (how?). With Argyris and Schön (1978), we argue for a reflective practice, in which meaningful actions toward change are well connected to underlying assumptions. In the societal setting of sustainability transitions, such actions often involve the concerted efforts of a group of people who did not collaborate earlier, hence the need to include relations (who?) as well. 
Our framework (see Figure 1) offers clear distinctions between process, outcome, and impact of learning: while societal change can be argued to start with communication, it does not take place without new real-world individual or collaborative actions. Thus, we draw distinctions between the discursive actions in the interaction patterns, the discursive learning outcomes that are part of the interaction, and the real-world actions that possibly follow. The latter actions are seen as the impact of social learning. Finally, regarding the relation between learning process and learning outcomes, insights from educational sciences have often uncovered relations between patterns of communicative actions and learning outcomes (albeit often in terms of achievement). McGregor and Chi (2002) indicate that interactive patterns of peer observation, argumentation, self-explanation and criticizing underlie successful collaborative learning. Webb (1989) found that the level of elaboration in collaboration was positively related to student achievement. Thus, it stands to reason that different types of communicative interaction will occur during social learning, for instance, as different interactive episodes during meetings, and that these patterns will be related to different types of outcomes. Thus, we expect that types of discursive interaction influence social learning outcomes.

Fig. 1. Learning as a discursive process with interwoven knowledge, relations, and actions as outcomes

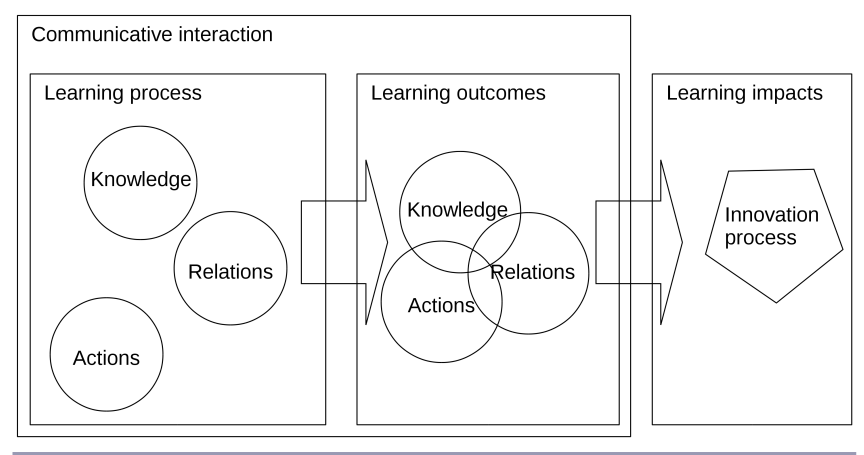

Toward an integrative approach: methodological considerations Our view of social learning has several methodological repercussions. First of all, although facilitated interaction can be part of a social learning process, we see it essentially as the more natural communication that takes place over longer time periods within various configurations within and across the network of an innovation initiative. In the practice of transition initiatives, social learning takes place in an ongoing chain of interactions, like in meetings, phone calls, and email exchanges. Each such interactive situation offers a discursive space (Leeuwis and Aarts 2011) that can (re-)establish, reinforce and/or change conceptual outcomes, relational outcomes, and actions. Over the course of its existence, an innovation initiative will see a host of consecutive discursive spaces across a wide network of innovators and others. This means that data need to be collected over a longer period of time, spanning multiple meetings, ideally in multiple configurations and settings in a network. Also, it means we study meetings as organized by initiatives themselves instead of workshops conducted by researchers.
Second, our view of social learning as a discursive process with discursively established learning outcomes suggests studying dominant patterns of utterances and responses (communicative turns), in line with discursive psychology, but at a slightly higher level of aggregation. Therefore we document the communicative interaction itself as data, be it in the form of extensive notes, audio recordings or full transcripts of meetings, to analyze (1) patterns of communicative interaction, and (2) interwoven knowledge, relations, and actions, that is, the moments of learning as an outcome. The main research question to explore the framework is: how can social learning be characterized in terms of different patterns of communicative interaction, and how are these patterns related to social learning outcomes?

\section{METHODS}

We followed an innovation initiative of Dutch greenhouse growers for seven months. It was studied using Reflexive Monitoring in Action, a novel and integrated action research methodology that facilitates initiatives and programs in the process of designing more sustainable systems by stimulating reflection on the institutional setting and interactive learning (Van Mierlo et al. 2010a, Van Mierlo et al. 2010c).

An action research approach was necessary to gain legitimate access to the meetings of our case. As a service in return for collecting data, we offered support to the initiative by reflecting on both ongoing interactive processes and the initiative as a whole from a transition science perspective. We analyzed (1) the interactive patterns, (2) the learning outcomes, and (3) the associated impacts as they occurred during our study.

\section{Case}

STAP is an innovation initiative of greenhouse growers. STAP means Foundation for Strengthening the Sales and Marketing Position of Greenhouse Vegetable Producers in the Netherlands (in Dutch: STichting versterking Afzetpositie Producenten van glasgroenten in Nederland). STAP was founded around AugustSeptember 2011 and is a network of greenhouse growers, researchers, educational institutes, and intermediaries. At the beginning of our study, STAP consisted of an executive board and a larger general board, both composed mainly of greenhouse growers. Furthermore, STAP was setting up a platform of universities, educational organizations, and intermediaries, which became established as the chain knowledge platform during our study. This platform consisted of a member of the STAP executive board, two researchers, two innovation advisers, and a higher professional education institute representative. These actors brought together different resources and perspectives relevant for making the greenhouse value chain more societally responsive.

STAP's goal was to innovate the greenhouse sector in order to make it more market oriented, as a way of dealing with the poor market position of greenhouse growers. The underlying assumption seemed to be that, without change, the sector would be economically unsustainable. Prior to this study, STAP had organized workshops for growers to raise awareness about the issues facing the greenhouse sector, but these workshops did not result in the actual innovations necessary to change the sector. At the beginning of our involvement, STAP was looking for new strategies for innovation, aimed mainly at striking new alliances 
with actors further down the production chain. Soon after, its efforts started going beyond a pure market orientation, and increasingly focused on transition toward a societally sensitive greenhouse sector, including environmental considerations (such as climate change, energy use, and food waste) and public interests (such as dietary health considerations and transparency of information of greenhouse produce).

\section{Data}

For this study, we attended two meetings of the general board and seven of the chain knowledge platform in the period January to July 2013. The meetings were documented in the form of extensive notes on six meetings as well as complete transcripts for another three. We used this data for the analysis of: (1) the type of interaction in meetings, (2) the learning outcomes in terms of interwoven knowledge, relations, and actions, and (3) the impact of the learning outcomes in the innovation initiative. In addition, we conducted seven phone calls, five interviews with greenhouse growers, and screened six project documents and other documents that were distributed in preparation for the meetings. We used the phone calls to verify whether decisions during the meetings had actually been followed through (the impact of the learning outcomes), for those instances when this was not clear from the subsequent meetings themselves. The interviews with greenhouse growers were semi-structured, aimed at gaining a better understanding of the main obstacles to change in the Dutch greenhouse sector. They served as an asset to interpreting the content of the meetings. The other documents were used for preparation of agenda items, and therefore supported the analysis and interpretation of meeting content.

\section{Analysis}

The nine meetings of the STAP general board and the STAP chain knowledge platform were used as the prime source of data about the social learning process. Segmentation of the meeting data was done using a predefined segmentation procedure, which was based on similar coding procedures for the analysis of negotiation of common ground (Beers et al. 2007). The analysis began with segmenting each of the meeting notes/ transcripts into different interaction episodes. These episodes were used as the main unit of analysis in the remainder of the analysis. Episodes were identified as the communication around one conversation topic, not unlike how participants in a professional meeting treat an issue on their agenda. Furthermore, some parts of the conversation drifted more than they were on topic. Such drifting parts of the meeting were also treated as one interactive episode.

\section{Interaction type}

We used an open coding approach (Strauss 1987) to characterize the interaction within each episode, with the aim of distinguishing different types of interaction. Various condensing concepts were used to construct categories of interaction type. Specifically, we checked whether one person would dominate an episode, the others mainly acting as receivers of information, or whether most persons acted as contributing partners. We also paid attention to whether the interaction was characterized by an open, positive atmosphere or a more closed-down, negative atmosphere, not only based on how people reacted to each other, but also on changes in tone of voice and inflexion. Note, however, that the latter, aural aspects were not part of the resulting code definitions.
When a clear change in interaction type would occur in the midst of one episode, we split it into two code segments with separate codes for interaction.

The first author first analyzed the entire data set, carrying out both the segmentation and the initial coding of interaction. All resulting categories for interaction type were described and defined, after which the third author, who had already analyzed a similar case and was familiar with the types of interactions in STAP, sampled the data to check whether the codes were applied consistently. This led us to word the description for one of the identified patterns differently. Other than that, the third author mostly agreed with the analysis, barring the recoding of a few episodes. We identified six qualitatively different types of interaction.

\section{Learning outcomes}

Learning outcomes were coded per episode to ensure a close relation with the communicative interaction. An episode was coded as having resulted in learning if (1) it contained conceptual content, relational content, and actions, and (2) clear conceptual relations existed between these content types, and 3) at least one action discussed concerned a decision to carry out that action. Note that the latter is only a specification of actions, it does not make actions more important than conceptual content or relational content.

We first identified those episodes in which a decision was taken, those being the segments with the highest probability of having a learning outcome. Next, we coded the learning content of each of these episodes, distinguishing three main content categories, namely, conceptual content, relational content, and actions. This procedure led to the identification of 14 episodes with a learning outcome. Incidentally, this approach was problematic for those cases where a clear change in interaction occurred during discussions about one topic, because in those cases discussion about one topic spanned two interactive episodes. For these cases we decided to code both interaction types for one learning outcome. Hence the reason that we have 19 interaction episodes with associated learning outcomes for only 14 learning outcomes; five learning outcomes spanned two interactive episodes.

Action content was coded for any statement that included an actual decision or an opportunity for action. In that sense, action content does not necessarily entail a concrete decision. Many options for action can be mentioned (such as, "we'll organize an event, preferably with live cases") without an actual decision being taken. In our coding, we distinguished between action content as options for action and action content as decisions. A decision includes an explicit or entailed commitment to a future (material) action by one or more participants in the meeting. Furthermore, a proposal for action is sometimes put on the agenda, while during the meeting it becomes clear that the proposal has insufficient backing. Such content was coded action, even though the proposal, as is, was not accepted.

Conceptual content was coded for any statement describing the initiative, its context, or its problem orientation, such as: "There is a difference between producing for bulk and producing for Japan: Japan has much higher quality standards." Conceptual content, as we coded it, includes the current state of affairs in the initiative, problems, and challenges confronting the initiative, and 
goals, visions, strategies, and ways of working toward change. Other examples of conceptual content include illustrative stories about cases. Sometimes, conceptual content really concerns discussion about the meaning of a concept, e.g., "what do we mean by communication?"

Relational content was coded for data fragments about actors. Usually, this concerned actors outside the initiative, and their relations with (the goals of) the initiative. Relational utterances concern actors and their (1) activities and development, (2) constituency, (3) disposition toward the goals of the initiative (roughly: insiders vs. outsiders), (4) importance for the initiative, and (5) the desired position toward the initiative. Furthermore, aspects such as culture and practice of other actors were coded relational content, such as when someone remarked that we should speak the language of growers. Participants could be a member of multiple groups and they could also change groups over time (cf. Akkerman et al. 2008).

\section{Impact of learning}

For each episode with a learning outcome, we then used the complete data set to find out whether, and to what extent, the decisions from the learning episodes were acted upon in reality. Examples of these were found in the form of written documents, meetings held with students, and interviews with sector magazines. In various cases, we contacted meeting participants to check whether they had followed up on the actions decided, when data about impact was not available yet.

\section{RESULTS}

We first discuss the different types of interaction that emerged from the analysis and then discuss the learning outcomes that we identified across all meetings that we attended. We end with a short discussion of how the learning outcomes were related to the interaction patterns and learning impacts.

\section{Interaction types}

The meeting data gave rise to the identification of six qualitatively different types of interaction: (1) antithetic interaction, (2) synthetic interaction, (3) informing, (4) word-of-power, (5) agenda wars, and (6) conflict. We will describe these interaction types with examples excerpted from the data.

In the antithetic interactions, a proposal or similar contribution (a plan, a position on something, etc.) was introduced and debated or opposed, upon which it was, in the end, accepted or rejected ("it was only an idea..."). The interaction pattern involves "proponents", who introduce and defend the proposal, and "opponents", who point out shortcomings, concerns, and hesitations, sometimes including outright attacks. The proponents tried to address these concerns by refuting them or by amending the proposal. The basic rule seemed to be that the proposal would be rejected, unless all opponents' concerns had been addressed, either by amending the proposal or by negating the concern. Some antithetic episodes seemed a bit like a game, as if the opposition one offers increases one's status. In one specific case, participants seemed as if they were competing to be the most critical opponent.

Example:

$\mathrm{J}$ : My case: increasing the shelf life of tomatoes. PS: Why would you want that?

\begin{abstract}
J: To be less dependent on sales and trade.
C: I think that's a typically defensive mode.

PJ: This seems purely a strategy to create more space for yourself within the current situation. So, is this part of a strategy for structural innovation?

J: I don't know.
\end{abstract}

Synthetic interactions often started with someone introducing a topic for conversation, not specifically a proposal, to which others responded by using their knowledge to build upon and improve upon the contribution in question, and hence make it more acceptable. It appears to be a mode of interaction in which participants have the opportunity to make the contribution conform better to their own ideas and/or views. The basic rule, in this pattern, appears to be that the ideas put forward in the contribution or proposal were accepted, along with the additions from the other participants.

Example:

G: [After having introduced a presentation] I think we
can use this presentation for communication purposes of
STAP.
PD: Many growers think, hey, I'll do the same thing
[that's in your slides], but they should think much
broader. So don't make the presentation too concrete,
show which steps to take.
C: Show the process
G: So more process?

The informing interaction pattern typically concerned one participant sharing information with the other participants, without the information in question being discussed. Instead, the other participants only listened, and in a rare case asked for clarification, without any apparent strategic objective. A typical example would be a round of news and messages in a meeting; every member may share some messages that he/she thinks are informative to the others, but usually without the aim of starting a discussion or choosing a course of action. For example: "The students have started their project with the small-scale greenhouse growers."

Example:

PJ: I wrote a few recommendations for STAP Executive Board. Perhaps they're also interesting for the CKP. I can share them.

PD: Yes. No. I saw them.

A: You already received that?

PD: Nothing crazy. No?

PS. Yes. Yesyesyesyes.

PD: Wasn't strange at all.

The "word-of-power" pattern involves one participant using his/ her position to overrule the deliberations of the group as a whole in reaction to an ongoing discussion or issue. In the case of wordof-power, one person with sufficient power takes a decision, seemingly regardless of the meeting's proceedings up until then.

Example:

PD: This still has to be approved.

G: No, approval was granted.

PD: Not by me. 
G: I have an email by $X$, so you didn't coordinate well internally.

PD: This is not going out. Not within the next three months.

Agenda wars are interaction episodes in which one or more people actively try to steer the conversation to a topic not explicitly on the agenda, but without explicitly mentioning this. These episodes are characterized by people reacting to a previous speaker, while trying to change the subject. This code was often used for episodes in which the topic appeared to drift between two or even three topics. The description might suggest that participants were avoiding a specific topic of conversation, but our data actually suggest that their efforts were more directed at putting a new topic on the table than getting the initial topic off the table. It thus appears that participants sometimes tried to raise a topic without appearing to do so. If successful, it would mean that they need not explain their reasons why. Agenda wars is the only interaction pattern we found that was characterized by multiple drifting conversation topics.

Example:

PJ: One of our conclusions was- what are we, the CKP, going to achieve for STAP. To work effectively, STAP needs a vision. If STAP formulates a vision, we can work much more effectively towards STAP's goals.

C: So what you're actually saying is that we're not limited to one production link, but we can tangle with the entire production chain.

Note in the example, how the first speaker wants to address STAP vision and the CKP effectiveness, whereas the second speaker wants to speak about the scope of the CKP. The way this example unfolded was that the first topic was not discussed in the end.

Conflict was coded for episodes in which one participant voiced an action, view, or position and another voiced his or her discontent about these actions, views, or positions. A participant for instance complained that a meeting had been too "political". In some cases, conflicts were resolved, for instance, when one participant reassured another that he was fully committed to the initiative after his position had caused some doubts, but this did not always happen.

Example:

C: If you think that the knowledge institutions are going
to payfor the attendance of the entrepreneurs then I think
you're on the wrong track, 'cause that's not going to
happen.
PS: Well, it might be the wrong track, but if that's the
way to the future, then those knowledge institutions can
goaheadand close down, as far as I'mconcerned, because
all policies are currently aimed at involving
entrepreneurs. And when [knowledge institutions] use
public funding when at the same time they say that
entrepreneurs can pay for themselves, then that disgusts
me.

We observed several similarities and differences between the various patterns, especially regarding the informing pattern. The informing pattern differed from the antithetic and synthetic patterns with regard to whether or not participants use their own knowledge to give a reaction. In informing interaction, participants may ask some questions for clarification, but they do not use their knowledge to attack or build upon the information shared. Incidentally, many participants gave criticisms by asking questions. Such questions might come across as informative, but they actually belong to synthetic or antithetic interaction, and not to informing. The informing pattern was similar to word-of-power in the sense that the other participants' knowledge appears not to inform the resulting decision. However, in the word-of-power pattern we still hear others' knowledge and insights, which is not the case in the informing pattern.

The synthetic and antithetic patterns were most intense in terms of the exchange of ideas. In these patterns, many, if not all, participants shared their own views, either to criticize (antithetic) or build upon each other (synthetic). In contrast, the informing and word-of-power interaction types did not include an exchange of ideas. Rather, they involved one member informing the others, or deciding for the others, while the others' opinions were either not voiced (informing) or not taken into account in the outcome (word-of-power).

\section{Learning Outcomes}

In the nine meetings observed, we identified 14 episodes with learning outcomes, that is, an interweaving of knowledge, relations, and actions in the communicative interaction (see Table 1). So, on average, in the STAP case one meeting included about one or two learning outcomes, sometimes as many as four. A good example of the learning outcomes identified in the Chain Knowledge Platform ("Student behaviors in projects for growers" in Table 1) is:

- Knowledge: The recently implemented new role for Higher Professional Education [i.e., students working with regional businesses as part of their education] needs some more getting used to among teachers and students. If students are presented with overly broad questions, they think too long and are too slow to understand the complexity. If students don't make weekly reports, then they cannot become good managers, nor can they offer guidance to entrepreneurs.

- Relations: It is suggested to be difficult for students to gain entry to trading companies.

- Actions - decision: In response to the discussion with the CKP, the Higher Professional Education institute will no longer put students in a creative-productive role, but in a productive role only, and they will have to write weekly reports.

Relations with interaction patterns and impact

Table 2 shows the frequencies of the various interaction types, learning outcomes, and impacts. For a substantive description of these aspects for each learning outcome, see Table 1. Synthetic interaction and informing are the most predominant interaction types. Four patterns were associated with concrete learning outcomes: (1) synthetic interaction; (2) antithetic interaction; (3) word-of-power; and (4) informing. The agenda wars and conflicts did not lead to learning outcomes. Antithetic episodes interestingly number only a small proportion of total episodes while leading relatively often to learning outcomes, and even sharing the first rank among learning outcomes with immediate impact, together with synthetic interaction. 
Table 1. Social learning outcomes

\begin{tabular}{lll}
\hline \hline Topic & Date $^{\dagger}$ Interaction & Immediate impact \\
\hline Perspectives on "bundling" & $12-02$ Synthetic & Short note on bundling \\
Student projects with 4 ha growers & $12-02$ Informing & Report available but no follow-up \\
Formation of a Chain Knowledge Platform & $20-02$ Antithetic/ Informing & Chain Knowledge Platform established and active \\
Workshops for growers and the creative industries & $05-03$ Antithetic & No follow-up \\
STAP will participate in the "Chain Security" project & $05-03$ Word-of-Power & Unknown \\
Discussion about note on bundling & $16-04$ Antithetic & Revised note about bundling \\
STAP "Statement-of-Urgency" and financial resources & $08-05$ Synthetic & None of the actions followed up \\
Marketing cases & $13-05$ Synthetic/ Word-of-Power & Unknown \\
Discussion about revised note on bundling & $13-05$ Antithetic & Short note prompted for publicity \\
Publicity about bundling & $03-06$ Synthetic & No direct follow-up \\
The Chain Knowledge Platform's mandate & $03-06$ Synthetic & No direct follow-up \\
The Chain Knowledge Platform's members and their & $03-06$ Synthetic & their position \\
interests & & Changes in educational set-up \\
Student behaviors in projects for growers & $03-06$ Informing/ Synthetic & Joint meeting with a sales organisation \\
Shelf life and innovation & $25-06$ Synthetic/ Antithetic &
\end{tabular}

Table 2. Frequencies of interaction types, learning outcomes, and impact

\begin{tabular}{lccc}
\hline \hline Interaction type & Frequency & $\begin{array}{c}\text { With learning } \\
\text { outcome }\end{array}$ & $\begin{array}{c}\text { With known } \\
\text { impact }\end{array}$ \\
\hline $\begin{array}{l}\text { Antithetic } \\
\text { interaction }\end{array}$ & 8 & 5 & 4 \\
$\begin{array}{l}\text { Synthetic } \\
\text { interaction }\end{array}$ & 25 & 8 & 4 \\
Informing & 26 & 2 & 2 \\
Word-of-power & 5 & 1 & 0 \\
$\begin{array}{l}\text { Agenda wars } \\
\text { Conflict }\end{array}$ & 4 & 0 & - \\
Total number of interactions with learning outcome exceeds total \\
learning outcomes, because some learning outcomes spanned multiple \\
(consecutive) interaction types. \\
${ }^{\ddagger}$ Episodes with unknown impact were treated as having no impact.
\end{tabular}

For each learning outcome, the immediate impact was charted (see Table 2, right-most column). Eight of the social learning outcomes were followed up with the physical actions agreed upon. On the other hand, even when a clear decision was taken, in six instances physical actions did not follow up on learning. For instance, in the eleventh learning outcome, it was learned that (1) the Chain Knowledge Platform needed to contact other value chain partners in order to be successful, and that (2) the growers from STAP supported this. However, to date no chain actor has attended the Chain Knowledge Platform. And the seventh learning outcome was not followed up at all. However, it must be noted that the original goal to form a coalition changed in the same period.

\section{CONCLUSION}

We aimed to develop an integrative perspective on social learning as a process taking place in the discursive interaction in and around a sustainability transition initiative. To this end, we developed an analytical framework for the relation between communicative interaction patterns, social learning outcomes, and the impact of social learning. The main research question was: how can social learning be characterized in terms of different patterns of communicative interaction, and how are these patterns related to social learning outcomes?

We established six qualitatively different patterns of communicative interaction in the attended meetings of the case study and identified 14 learning outcomes, spanning a total of 19 interactive episodes. This study has established that different patterns of communicative interaction indeed seem to be related to a different potential for producing learning outcomes, although this result cannot be generalized on the basis of this one case. The antithetic interaction episodes most often resulted in learning and impact.

Having established empirically different patterns of communicative interaction and their relations to learning outcomes is the first indication of the feasibility of our new framework. Our findings support the assumption that social learning can be regarded as discursive interaction with learning outcomes in terms of interwoven knowledge, relations, and action and that some interaction patterns are more closely connected to social learning than others.

\section{DISCUSSION}

Of the interaction patterns we found, two (antithetic and synthetic) are particularly on-topic and rich in exchange of knowledge and participation from actors with diverse perspectives. Surprisingly, the antithetic interaction episodes most often resulted in learning and impact. This contrasts with the predominantly "harmonious" or synthetic disposition toward social learning in the literature (Leeuwis 2000). Although several authors mention the role of conflict in learning (Leeuwis 2000, Cundill 2010), most emphasize social learning as a way of resolving conflict (Pahl-Wostl 2006), as a democratic approach based on inclusive "governance" (Bouwen and Taillieu 2004), and as requiring empathetic engagement (Leys and Vanclay 2011). Our results rather underscore the importance of having disagreement for social learning. Interestingly, this is in line with research by Van den Bossche et al. (2011:295-296), who found that having "constructive conflict" (cf. antithetic interaction) is 
positively related to building team mental models, whereas "coconstruction" ("complementing each other's information and ideas," cf. synthetic interaction) can even be detrimental to building team mental models. The results also possibly reflect our operationalization of learning, which includes decisions on actions. Learning thus assumes the implicit or explicit commitment of the various participants. Presumably, the need for commitment to actions urged the participants of STAP to be especially critical and engage in antithetic interaction. Vice versa, the research results suggest that antithetic interaction can help to establish commitment to a specific course of collective action.

The other interaction patterns may have different functions. An interesting associated question is how these results relate to the common notion in social learning literature that mutual differences can be an important resource in the context of complex societal problems. For instance, the synthetic interaction pattern appears more explorative with concepts and associated actions being pondered about and in which it is still "accepted" to ask for clarification. They appear to have some elements of negotiation of meaning (Beers et al. 2008), in which people explore their different perspectives. In the antithetic episodes, the participants rather appeared to confront each others' positions, to test whether a proposed action was sufficiently warranted. One might say that, perhaps, the antithetic episodes can be characterized by negotiation of position. Future research is needed to come to a better understanding of the relation between learning as interaction and learning as outcomes.

In light of previous criticisms on social learning, especially Reed et al. (2010), our research has taken various important steps, in the sense that:

- The learning process is explicitly conceptualized and analyzed;

- Learning process, outcomes, and impact have been conceptually and analytically separated;

- We analyzed (predominantly) natural communication and not workshop settings with facilitators;

- We studied an initiative over a longer time period, including multiple, related groups.

Some other authors have also suggested distinguishing between social learning process, outcomes, and impacts. Rodela (2011) provides an overview, in which, for example, the "individualcentric" perspective on social learning concerns individual transformation as process and behavioral change as outcome, and in which the "network-centric" perspective concerns learning from past experiences as process and changes in management practices as outcome. These perspectives still seem to conflate learning outcomes with either the process or the impact. The result is that the process is not operationalized, neither theoretically nor analytically, and that the outcomes and impact remain rather indistinguishable. Our approach operationalizes the learning process in terms of types of communicative patterns that are characterized by the ways in which speakers react to each other in conversation, that result in an outcome when the communicative aspects of issue content, relations, and actions become interwoven in a decision. The impact then is differentiated as the real-world effects of the decision, if it gets carried out.
In our view, the main innovation of our approach to social learning concerns how we analyzed interaction and how we related it to learning outcomes. Our approach offers an integration of process and outcomes of learning that establishes both learning process and outcomes as residing in communicative interaction, in line with educational sciences, while retaining the basic notion of social learning outcomes in the sense of changed knowledge, relations, and actions, in line with most of the literature on social learning. In that sense, it is similar to recent publications that also more clearly distinguish learning process from outcomes (e.g., Plummer and FitzGibbon 2008, Armitage et al. 2008, Lee and Krasny 2015). However, our approach additionally involves characterizing the process as communicative interaction and relating process characteristics to outcomes.

We further add to the literature in a methodological sense, by analyzing social learning occurring in the communication related to a change process of a transition initiative. This process approach sheds light on innovative ways of supporting social learning. Instead of trying to reach for the desired outcomes, or organizing specialized learning encounters, this process approach acknowledges the emergence of learning conditions directly in the innovation trajectory, in terms of relevant communicative interaction patterns.

The study reported here was based on a single case, covering an analysis period of over half a year, based on review of extensive meeting notes or verbatim meeting transcripts. While the analyses were rigorous and in-depth, the results cannot be generalized on this basis alone. We studied a Dutch case, which may have influenced our results. For example, Hofstede et al. (2010) have characterized Dutch society as relatively individualistic. Perhaps in a different cultural setting, the findings about the different interaction patterns and their relations would have turned out differently.

When it comes to learning in the sustainability transitions literature, our approach of social learning again adds a process orientation. Existing transition science literature does address various aspects of learning, especially regarding selecting insights from niche experiments (Raven et al. 2008, Raven and Geels 2010, cf. Rotmans and Loorbach 2009). This literature conceives of learning as a process of selecting lessons from niches, making sense of their meaning for other contexts, through a process of "social learning" (in quotation marks, since the meaning of the term differs from our use). In a sense, this overlaps with our approach, since the social aspect of sense making happens in interaction (cf. Bromme 2000). However, our approach includes more aspects of learning than sense making alone, and gives a more detailed account of how learning processes evolve among multiple actors.

With regard to supporting transitions processes, our results suggest first of all, that it should be possible to analyze learning outcomes as they emerge in interaction, doing an "on-line" analysis of learning during meetings of a transition initiative such as STAP. This can be done, for instance, by taking notes during a meeting and dividing them into knowledge, relations, and actions. In doing so, an innovation initiative may become more aware of its own learning process, which would help the learners to align their ideas, their network, and actions, in other words, to be more learning outcome oriented. Secondly, validation of the 
importance of various interaction patterns in the social learning process in future research would open a path to a fine-tuned way of process facilitation in which facilitators, for instance, detect when antithetic and synthetic interactions appear to be out of balance, and use this to advise the initiative's manager or participants on how to conduct the meetings more productively for social learning.

Responses to this article can be read online at: http://www.ecologyandsociety.org/issues/responses. $\mathrm{php} / 8148$

\section{Acknowledgments:}

This work is part of the research programme Responsible Innovation, which is (partly) financed by the Netherlands Organisation for Scientific Research (NWO). We would like to thank the anonymous reviewers and the subject editor for their comments on this article.

\section{LITERATURE CITED}

Akkerman, S., W. Admiraal, R.-J. Simons, and T. Niessen. 2008. Considering diversity: multivoicedness in international academic collaboration. Culture \& Psychology 12:461-485. http://dx.doi. org/10.1177/1354067x06069947

Argyris, C., and D. A. Schön. 1978. Organizational learning: a theory of action perspective. Addison-Wesley, Reading, Massachussetts, USA. http://dx.doi.org/10.2307/40183951

Armitage, D., M. Marschke, and R. Plummer. 2008. Adaptive comanagement and the paradox of learning. Global Environmental Change 18:86-98. http://dx.doi.org/10.1016/j.gloenvcha.2007.07.002

Baker, M. J., T. Hansen, R. Joiner, and D Traum. 1999. The role of grounding in collaborative learning tasks. Pages 31-63 in P. Dillenbourg, editor. Collaborative learning: cognitive and computational approaches. Pergamon/ Elsevier Science, Amsterdam, The Netherlands.

Barron, B. 2003. When smart groups fail. The Journal of the Learning Sciences 12(3):307-359. http://dx.doi.org/10.1207/ s15327809j1s1203_1

Barrows, H. S., and R. M. Tamblyn. 1980. Problem-Based Learning. An approach to medical education. Springer, New York, USA.

Beers, P. J., H. P. A. Boshuizen, P. A. Kirschner, and W. Gijselaers. 2007. The analysis of negotiation of common ground in CSCL. Learning and Instruction 17:427-435. http://dx.doi.org/10.1016/j. learninstruc.2007.04.002

Beers, P. J., H. P. A. Boshuizen, P. A. Kirschner, W. Gijselaers, and J. Westendorp. 2008. Cognitive load measurements and stimulated recall interviews for studying the effects of information and communications technology. Educational Technology Research and Development 56:309-328. http://dx.doi.org/10.1007/ s11423-006-9020-7

Bouwen, R., and T. Taillieu. 2004. Multi-party collaboration as social learning for interdependence: developing relational knowing for sustainable natural resource management. Journal of Community \& Applied Social Psychology 14:137-153. http://dx. doi.org/10.1002/casp.777

Bromme, R. 2000. Beyond one's own perspective: the psychology of cognitive interdisciplinarity. Pages 115-133 in P. Weingart, and N. Stehr, editors. Practicing interdisciplinarity. University of Toronto Press, Toronto, Canada.

Cundill, G. 2010. Monitoring social learning processes in adaptive comanagement: three case studies from South Africa. Ecology \& Society 15(3):28.

Dewulf, A., and R. Bouwen. 2012. Issue framing in conversations for change: discursive interaction strategies for "doing differences". The Journal of Applied Behavioral Science 48:168-193. http://dx.doi.org/10.1177/0021886312438858

Dillenbourg, P. 1999. What do you mean by 'collaborative learning'? Pages 1-19 in P. Dillenbourg, editor. Collaborative learning: cognitive and computational approaches. Elsevier, Oxford, UK.

Edmondson, A. 1999. Psychological safety and learning behavior in work teams. Administrative Science Quarterly 44:350-383. http://dx.doi.org/10.2307/2666999

Edwards, D., and J. Potter. 2001. Discursive psychology. Pages 12-24 in A. Mchoul, and M. Rapley, editors. How to analyse talk in institutional settings. Continuum, London, UK.

Hofstede, G., G. J. Hofstede, and M. Minkov. 2010. Cultures and organizations: software of the mind. McGraw-Hill, London, UK. http://dx.doi.org/10.1080/00208825.1980.11656300

Ison, R., C. Blackmore, and B. L. Iaquinto. 2013. Towards systemic and adaptive governance: exploring the revealing and concealing aspects of contemporary social-learning metaphors. Ecological Economics 87:34-42. $\underline{\text { http://dx.doi.org/10.1016/j. }}$ ecolecon.2012.12.016

Ison, R., N. Röling, and D. Watson. 2007. Challenges to science and society in the sustainable management and use of water: investigating the role of social learning. Environmental Science \& Policy 10:499-511. http://dx.doi.org/10.1016/j.envsci.2007.02.008

Ison, R., and D. Watson. 2007. Illuminating the possibilities for social learning in the management of Scotland's water. Ecology and Society 12(1):21. [online] URL: http://www.ecologyandsociety. org/vol12/iss1/art21/

Kirschner, P., J.-W. Strijbos, K. Kreijns, and P. J. Beers. 2004. Designing electronic collaborative learning environments. Educational Technology Research and Development 52(3):47-66. http://dx.doi.org/10.1007/bf02504675

Kouevi, A. T., B. van Mierlo, and C. Leeuwis. 2011. Repetitive discrepency between espoused and in-use action theories for fishery intervention in Grand-Popo, Benin. International Journal of Learning and Change 5(2):114-138.

Krasny, M. E., and W.-M. Roth. 2010. Environmental education for social-ecological system resilience: a perspective from activity theory. Environmental Education Research 16(5-6):545-558.

Lave, J., and E. Wenger. 1991. Situated learning: legitimate peripheral practice. Cambridge University Press, New York, USA. http://dx.doi.org/10.1017/cbo9780511815355 
Lee, E., and M. E. Krasny. 2015. The role of social learning for social-ecological systems in Korean village groves restoration. Ecology and Society 20(1):42. http://dx.doi.org/10.5751/ ES-07289-200142

Leeuwis, C. 2000. Reconceptualizing participation for sustainable rural development: towards a negotiation approach. Development and Change 31:931-959. http://dx.doi.org/10.1111/1467-7660.00184

Leeuwis, C., and N. Aarts. 2011. Rethinking communication in innovation processes: creating space for change in complex systems. Journal of Agricultural Education and Extension 17:21-36. http://dx.doi.org/10.1080/1389224X.2011.536344

Leys, A. J., and J. K. Vanclay. 2011. Stakeholder engagement in social learning to resolve controversies over land-use change to plantation forestry. Regional Environmental Change 11:175-190. http://dx.doi.org/10.1007/s10113-010-0132-6

Loorbach, D., and J. Rotmans 2006. Managing transitions for sustainable development. Pages 187-206 in X. Olsthoorn, and A. J. Wieczorek, editors. Understanding industrial transformation: views from different disciplines, Vol. 44. Springer, Dordrecht, The Netherlands. http://dx.doi.org/10.1007/1-4020-4418-6_10

Mcgregor, M. U., and M. T. H. Chi. 2002. Collaborative interactions: the process of joint production and individual reuse of novel ideas. Pages 655-660 in W. D. Gray, and C. Schunn, editors. Proceedings of the Twenty-Fourth Annual Conference of the Cognitive Science Society. George Mason University, Fairfax, Virginia, USA.

Noroozi, O., A. Weinberger, H. J. A. Biemans, M. Mulder, and M. Chizari. 2012. Argumentation-based Computer Supported Collaborative Learning (ABCSCL): a synthesis of 15 years research. Educational Research Review 7(2):79-106

Pahl-Wostl, C. 2006. The importance of social learning in restoring the multifunctionality of rivers and floodplains. Ecology and Society 11(1):10. [online] URL: http://www.ecologyandsociety. org/vol11/iss1/art10/

Plummer, R., and J. FitzGibbon. 2008. Connecting adaptive comanagement, social learning, and social capital through theory and practice. Pages 38-61 in F. Berkes, D. Armitage, and N. Doubleday, editors. Adaptive co-management: collaboration, learning, and multi-level governance. University of British Columbia Press, Vancouver, British Columbia, Canada.

Raven, R. P. J. M., and F. W. Geels. 2010. Socio-cognitive evolution in niche development: comparative analysis of biogas development in Denmark and the Netherlands (1973-2004). Technovation 30:87-99. http://dx.doi.org/10.1016/j.

technovation.2009.08.006

Raven, R. P. J. M., E. Heiskanen, R. Lovio, and B. Brohmann. 2008. The contribution of local experiments and negotiation processes to field-level learning in emerging (niche) technologies: meta-analysis of 27 new energy projects in Europe. Bulletin of Science, Technology \& Society 28:464-477.

Reed, M. S., A. C. Evely, G. Cundill, I. Fazey, J. Glass, A. Laing, J. Newig, B. Parrish, C. Prell, C. Raymond, and L. C. Stringer. 2010. What is social learning? Ecology and Society 15(4):resp1. [online] URL: http://www.ecologyandsociety.org/vol15/iss4/ $\underline{\text { resp1/ }}$
Rodela, R. 2011. Social learning and natural resource management: the emergence of three research perspectives. Ecology and Society 16(4):30. http://dx.doi.org/10.5751/ es-04554-160430

Rotmans, J., and D. Loorbach. 2009. Complexity and transition management. Journal of Industrial Ecology 13:184-196. http://dx. doi.org/10.1111/j.1530-9290.2009.00116.x

Salomon, G., and D. N. Perkins. 1998. Individual and social aspects of learning. Review of Research in Education 23:1-24.

Schmidt, H. G. 1983. Problem-based learning: rationale and description. Medical Education 17:11-16. http://dx.doi. org/10.1111/j.1365-2923.1983.tb01086.x

Schmidt, H. G., S. M. M. Loyens, T. Van Gog, and F. Paas. 2007. Problem-based learning is compatible with human cognitive architecture: commentary on Kirschner, Sweller, and Clark (2006). Educational Psychologist 42:91-97. http://dx.doi. org/10.1080/00461520701263350

Scholz, G., A. Dewulf, and C. Pahl-Wostl. 2014. An analytical framework of social learning facilitated by participatory methods. Systemic Practice and Action Research 27:575-591.

Smith, B. L., and J. T. MacGregor. 1992. What is collaborative learning? Pages 10-30 in A. Goodsell, M. Maher, V. Tinto, B. L. Smith, and J. T. MacGregor, editors. Collaborative learning: a sourcebook for higher education. National Center on Postsecondary Teaching, Learning, and Assessment, University Park, Pennsylvania, USA.

Sol, J., P. J. Beers, and A. E. J. Wals. 2013. Social learning in regional innovation networks: trust, commitment and reframing as emergent properties of interaction. Journal of Cleaner Production 49:35-43. http://dx.doi.org/10.1016/j.jclepro.2012.07.041

Strauss, A. L. 1987. Qualitative analysis for social scientists. Cambridge University Press, Cambridge, UK. http://dx.doi. org/10.1017/cbo9780511557842

Sullivan Palincsar, A. 1998. Social constructivist perspectives on teaching and learning. Annual Review of Psychology 49:345-375. http://dx.doi.org/10.1146/annurev.psych.49.1.345

Suthers, D. D. 2001. Towards a systematic study of representational guidance for collaborative learning discourse. Journal of Universal Computer Science 7(3):254-277.

Van den Bossche, P., W. H. Gijselaers, M. Segers, and P. A. Kirschner. 2006. Social and cognitive factors driving teamwork in collaborative learning environments. Team learning beliefs and behaviors. Small Group Research 37(5):490-521.

Van den Bossche, P., W. Gijselaers, M. Segers, G. Woltjer, and P. Kirschner. 2011. Team learning: building shared mental models. Instructional Science 39:283-301. http://dx.doi.org/10.1007/ s11251-010-9128-3

Van der Velden, N. J. A., and P. X. Smit. 2014. Energiemonitor van de Nederlandse glastuinbouw 2013. LEI report 2014-025. LEI Wageningen UR, The Hague, The Netherlands.

Van Mierlo, B., M. Arkesteijn, and C. Leeuwis. 2010a. Enhancing the reflexivity of system innovation projects with system analyses. American Journal of Evaluation 31:143-161. 
Van Mierlo, B., C. Leeuwis, R. Smits, and R. Klein Woolthuis. $2010 \mathrm{~b}$. Learning towards system innovation: evaluating a systemic instrument. Technological Forecasting and Social Change 77:318-334.

Van Mierlo, B., B. Regeer, M. Van Amstel, M. Arkesteijn, V. Beekman, J. Bunders, T. De Cock Buning, B. Elzen, A.-C. Hoes, and C. Leeuwis. 2010c. Reflexive monitoring in action: a guide for monitoring system innovation projects. Boxpress, Oisterwijk, The Netherlands.

Veldkamp, A., A. C. van Altvorst, R. Eweg, E. Jacobsen, A. van Kleef, H. van Latesteijn, S. Mager, H. Mommaas, P. J. A. M. Smeets, L. Spaans, and J. C. M. van Trijp. 2009. Triggering transitions towards sustainable development of the Dutch agricultural sector: TransForum's approach. Agronomy for Sustainable Development 29:87-96. http://dx.doi.org/10.1051/ agro:2008022

Wals, A. E. J., editor. 2007. Social learning towards a sustainable world. Wageningen Academic Publishers, Wageningen, The Netherlands. http://dx.doi.org/10.3920/978-90-8686-594-9

Webb, N. M. 1989. Peer interaction and learning in small groups. International Journal of Educational Research 13:21-39. http://dx. doi.org/10.1016/0883-0355(89)90014-1

Wenger, E. 1998. Communities of practice: learning, meaning and identity. Cambridge University Press, Cambridge, UK. http://dx. doi.org/10.1017/cbo9780511803932 